\title{
STABILITY-INDICATING METHOD DEVELOPMENT AND VALIDATION OF ITRACONAZOLE AND TERBINAFINE HCL IN BULK AND PHARMACEUTICAL TABLET DOSAGE FORM
}

\author{
DEVYANI M RODE, Dr. NUTAN RAO* \\ Department of Pharmaceutical Chemistry and Quality Assurance, Oriental College of Pharmacy, Sector 2, Sanpada West, Navi Mumbai, \\ Maharashtra, India. Email: nutan.rao@ocp.edu.in
}

Received: 25 June 2019, Revised and Accepted: 27 June 2019

\section{ABSTRACT}

Objective: The objective of the present work was to develop and validate the stability-indicating method for the simultaneous estimation of itraconazole and terbinafine $\mathrm{HCl}$ in bulk and pharmaceutical tablet dosage form by reversed-phase high-performance liquid chromatography (HPLC). This combination of drugs is not reported for simultaneous HPLC analysis as of now.

Methods: The analysis of the developed method was carried on Shimadzu LC Prominence-i 2030 model with Lab Solution software and the separation was done on Shim-pack C18 GIST ( $250 \mathrm{~mm} \times 50 \mathrm{~mm}, 5 \mu \mathrm{m}$ ) column with a flow rate of $1.2 \mathrm{ml} / \mathrm{min}$ and run time of $12 \mathrm{~min}$. The injection volume was $10 \mu \mathrm{l}$ and mobile phase consisted of acetonitrile and $0.1 \%$ triethylamine in the ratio of $90: 10$ and $225 \mathrm{~nm}$ was used as a detection wavelength.

Results: The retention time was found to be $3.464 \mathrm{~min}$ and $8.705 \mathrm{~min}$ for itraconazole and terbinafine $\mathrm{HCl}$, respectively. The calibration curve was found to be linear and $\mathrm{r}^{2}$ values were 0.9989 and 0.9995 for itraconazole and terbinafine $\mathrm{HCl}$, respectively.

Conclusion: The stability-indicating method was developed by subjecting itraconazole and terbinafine $\mathrm{HCl}$ marketed formulation to various stress conditions such as acidic, basic, oxidative, thermal, and water hydrolysis degradation conditions and the degraded product peaks were well resolved from sample peaks.

Keywords: Itraconazole, Terbinafine $\mathrm{HCl}$, Reversed-phase high-performance liquid chromatography, Validation, Degradation.

(c) 2019 The Authors. Published by Innovare Academic Sciences Pvt Ltd. This is an open access article under the CC BY license (http://creativecommons. org/licenses/by/4. 0/) DOI: http://dx.doi.org/10.22159/ajpcr.2019.v12i9.33922

\section{INTRODUCTION}

Both itraconazole and terbinafine $\mathrm{HCl}$ are antifungal drugs. The International Union of Pure and Applied Chemistry name of itraconazole and terbinafine $\mathrm{HCl}$ is 4-[4-[4-[4-[[cis-2-(2,4-dichlorophenyl)-2(1H-1,2,4-triazol-1-ylmethyl)-1,3dioxolan-4-yl] methoxy] phenyl] piperazin-1-yl] phenyl]-2-[(1RS)-1methylpropyl]-2,4-dihydro-3H-1,2,4triazol-3-one] and (E)-N,6,6-trimethyl-N-(naphthalen-1-ylmethyl) hept2-en-4-yn-1 amine hydrochloride respectively. The chemical formula of itraconazole and terbinafine $\mathrm{HCl}$ is $\mathrm{C}_{35} \mathrm{H}_{38} \mathrm{C}_{12} \mathrm{~N}_{8} \mathrm{O}_{4}$ and $\mathrm{C}_{21} \mathrm{H}{ }_{25} \mathrm{~N} \cdot \mathrm{HCl}$, respectively, and molecular weight is $706 \mathrm{~g} / \mathrm{mol}$ and $327.89084 \mathrm{~g} / \mathrm{mol}$, respectively [1,2]. Itraconazole and terbinafine $\mathrm{HCl}$ both are freely soluble in acetonitrile, methanol, and dimethyl sulfoxide but insoluble in water $[1,2]$. The chemical structure of both drugs is given in Figs. 1 and 2.

Combination of itraconazole and terbinafine $\mathrm{HCl}$ is used for the treatment of antifungal infections such as toenail onychomycosis and it stops the growth of fungi by preventing covering [3]. The literature survey reveals that there is no reversed-phase high-performance liquid chromatography (RP-HPLC) method reported for the estimation of itraconazole and terbinafine $\mathrm{HCl}$ in tablet dosage form [4-8]. Thus, the present work was carried out to develop novel, precise, accurate, rapid, and cost-effective stability-indicating method and to validate the method for simultaneous estimation of itraconazole and terbinafine $\mathrm{HCl}$ in tablet dosage form and its application for the separation of the peak of a degradation product.

\section{METHODS}

\section{Instrument}

RP-HPLC Shimadzu LC Prominence-i 2030 model and Lab Solution software were used for stability-indicating method development and validation of itraconazole and terbinafine $\mathrm{HCl}$. The BIO-LAB (BL-135 D) centrifuge model was used for centrifugation of sample; Kroma Tech (KL-1.5) sonicator was used for sonication and hot air oven EXPO HITECH was used for thermal degradation.

\section{Chemicals and reagents}

Itraconazole and terbinafine $\mathrm{HCl}$ were provided by Alkem Laboratories, Navi Mumbai, Maharashtra, India, and commercial tablet dosage form Duofaze was purchased from a local market. The HPLC grade acetonitrile was purchased from Qualigens Thermo Fisher Scientific. Analytical grade triethylamine (TEA), hydrochloric acid, sodium hydroxide, and hydrogen peroxide were purchased from S.D Fine Chemicals.

\section{Chromatographic conditions}

The separation of itraconazole and terbinafine $\mathrm{HCl}$ was carried out using Shimadzu RP-HPLC system with Shim-pack GIST C18 $(250 \mathrm{~mm} \times 4.6 \mathrm{~mm}, 5 \mu)$ column. The mobile phase used was acetonitrile and $0.1 \%$ TEA in the ratio $(90: 10)$ at a flow rate of $1.2 \mathrm{ml} / \mathrm{min}$, injection volume was $10 \mu \mathrm{l}$, column temperature was $\left(30^{\circ} \mathrm{C}\right)$, and itraconazole and terbinafine $\mathrm{HCl}$ were detected at $225 \mathrm{~nm}$ using an ultraviolet (UV)-visible detector.

\section{Selection of wavelength}

Standard solutions of itraconazole $(10 \mathrm{ppm})$ and terbinafine hydrochloride (10 ppm) were prepared and scanned by UV spectrophotometer separately, in the range of $200-400 \mathrm{~nm}$ and overlay UV spectra of itraconazole and terbinafine $\mathrm{HCl}$ obtained are shown in Fig. 3. The $225 \mathrm{~nm}$ wavelength was selected as detection wavelength for the separation of itraconazole and terbinafine $\mathrm{HCl}$.

Preparation of $0.1 \%$ TEA

Add $1 \mathrm{ml}$ of TEA in $1000 \mathrm{ml}$ of deionized water. 
Preparation of mobile phase

A mixture of 90 volumes of HPLC grade acetonitrile and 10 volumes of TEA was prepared and sonicated for 10-15 min to degas.

\section{Preparation of standard solution}

Standard solution of itraconazole and terbinafine $\mathrm{HCl}$ was prepared by dissolving $10 \mathrm{mg}$ of itraconazole and $25 \mathrm{mg}$ of terbinafine hydrochloride reference standards into $250 \mathrm{ml}$ volumetric flask. About $150 \mathrm{ml}$ of acetonitrile was added as a diluent and sonicated for 15-20 min and the volume was made up to the mark using acetonitrile, to obtain a concentration of $40 \mathrm{ppm}$ of itraconazole and $100 \mathrm{ppm}$ of terbinafine hydrochloride, respectively.

\section{Preparation of sample solution}

Ten tablets were weighed and finely powdered and quantity corresponding to $80 \mathrm{mg}$ of (itraconazole + terbinafine $\mathrm{HCl}$ ) was taken and transferred to a $250 \mathrm{ml}$ volumetric flask and $150 \mathrm{ml}$ of diluent was added. The flask was sonicated for 30-45 min with intermittent shaking. Volume was adjusted up to the mark with diluent. Sample solution was centrifuged at $5000 \mathrm{rpm}$ for $10 \mathrm{~min}$ and then filtered through Whatman filter paper.

\section{Method validation}

The developed method for itraconazole and terbinafine $\mathrm{HCl}$ was validated for parameters such as system suitability, precision, linearity, accuracy, robustness, and solution stability as per ICH guidelines [9-12].

\section{Forced degradation studies}

Forced degradation is the process, in which pure drug and drug products are subjected to chemical and environmental stress conditions to know the degradation pathway of drug and degradation products which can be used to determine the stability of the drug [13]. For acid and alkali stress conditions, $5 \mathrm{ml}$ of $0.1 \mathrm{~N} \mathrm{HCl}$ and $0.1 \mathrm{~N} \mathrm{NaOH}$ were added, respectively, and kept at $60^{\circ} \mathrm{C}$ for $1 \mathrm{~h}$, for oxidative degradation, $5 \mathrm{ml}$ of $30 \% \mathrm{H}_{2} \mathrm{O}_{2}$ was added and kept at $60^{\circ} \mathrm{C}$ for $1 \mathrm{~h}$, and $5 \mathrm{ml}$ of water added

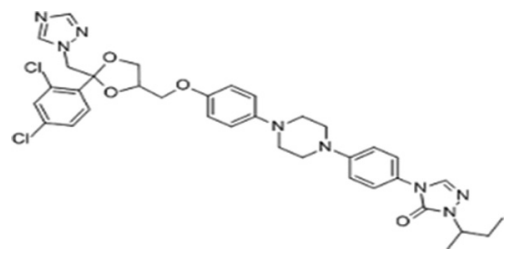

Fig. 1: Chemical structure of itraconazole

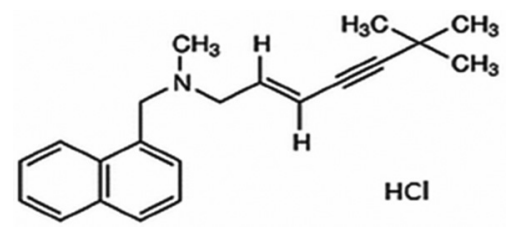

Fig. 2: Chemical structure of terbinafine $\mathrm{HCl}$

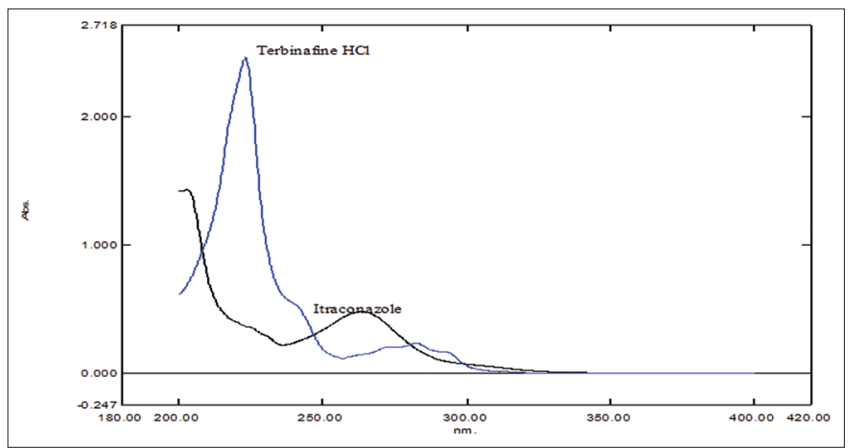

Fig. 3: Ultraviolet overlain spectra of itraconazole and terbinafine $\mathrm{HCl}$ and kept at $60^{\circ} \mathrm{C}$ for $1 \mathrm{~h}$ for water hydrolysis degradation. Thermal degradation was performed by keeping the sample in a Petri dish and then placed them in an oven at $60^{\circ} \mathrm{C}$ for $1 \mathrm{~h}$.

\section{RESULTS AND DISCUSSION}

\section{Method development}

A series of trials were carried out using different mobile phases such as acetonitrile:water (50:50), methanol:water (50:50), and acetonitrile:1\% oil pollution act (90:10) and using different columns such as Inertsil ODS, Prontosil, and Shim-pack C18 to develop RP-HPLC method for simultaneous estimation of itraconazole and terbinafine $\mathrm{HCl}$ in marketed tablet dosage form. Finally, a typical chromatogram was obtained using acetonitrile and $0.1 \%$ TEA as mobile phase in a ratio of 90:10 on Shim-pack GIST C18 (250 mm×4.6 mm, $5 \mu)$ column and injection volume of $10 \mu \mathrm{l}$. The flow rate was $1.2 \mathrm{ml} / \mathrm{min}$ and the run time was $12 \mathrm{~min}$. The column temperature was $30^{\circ} \mathrm{C}$ and detection was carried out at $225 \mathrm{~nm}$. The retention time was $3.4 \mathrm{~min}$ and 8.7 min for itraconazole and terbinafine $\mathrm{HCl}$, respectively. Typical chromatograms of standard and sample solution of itraconazole and terbinafine $\mathrm{HCl}$ are shown in Figs. 4 and 5. The same developed method was applied for forced degradation studies of itraconazole and terbinafine $\mathrm{HCl}$ marketed tablet dosage form, and degraded product peak was well separated using this developed method. The optimized chromatographic conditions are tabulated in Table 1.

Table 1: Optimized chromatographic conditions for itraconazole and terbinafine $\mathrm{HCl}$

\begin{tabular}{ll}
\hline Parameters & Optimized conditions \\
\hline Column & Shimpack C18 $(250 \mathrm{~mm} \times 4.6 \mathrm{~mm}, 5 \mu)$ \\
Mobile phase & Acetonitrile and 0.1\% triethylamine in the \\
& ratio of $90: 10$ \\
Diluent & Acetonitrile \\
Column temperature & $30^{\circ} \mathrm{C}$ \\
Wavelength & $225 \mathrm{~nm}$ \\
Flow rate & $1.2 \mathrm{ml} / \mathrm{min}$ \\
Injection volume & $10 \mu \mathrm{l}$ \\
Run time & $12 \mathrm{~min}$ \\
Retention time & 3.464 and $8.705 \mathrm{~min}$ \\
\hline
\end{tabular}

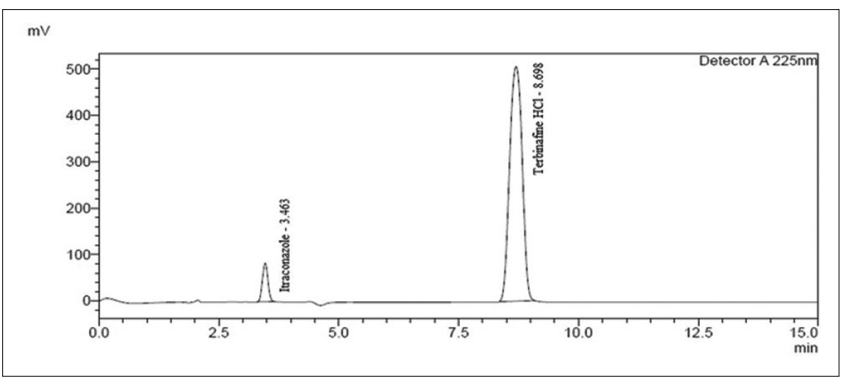

Fig. 4: Typical chromatogram of a standard mixture of itraconazole and terbinafine $\mathrm{HCl}$

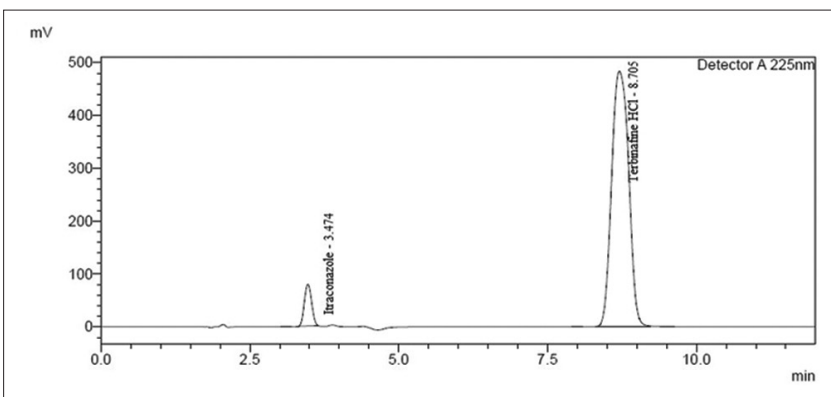

Fig. 5: Typical chromatogram of a sample of itraconazole and terbinafine $\mathrm{HCl}$ 
System suitability

System suitability was done by injecting six replicates injection of the standard solution and retention time, tailing factor, and number of theoretical plate were evaluated. The standard solutions of itraconazole and terbinafine $\mathrm{HCl}$ were prepared as per the above method and injected into a chromatographic system. System suitability parameters such as number of theoretical plates, tailing factor, and resolution were evaluated. All the results of system suitability parameter are tabulated in Table 2 and all parameter results are within the limit.

\section{Precision}

The precision of an analytical procedure may be defined as the closeness of agreement between a series of measurements obtained from multiple sampling of the same homogeneous sample under the prescribed conditions. The system precision and method precision were performed by injecting six injections of itraconazole and terbinafine $\mathrm{HCl}$ standard and sample of the same concentration [14]. The percentage relative standard deviation (\% RSD) was calculated from the chromatogram area and it is $<2 \%$. From precision results, it was found that the method is precise. The data of system and method precision are tabulated in Table 3.

\section{Accuracy}

The accuracy of itraconazole and terbinafine $\mathrm{HCl}$ was performed by calculating recovery studies of the test sample at three different concentration levels $(50 \%, 100 \%$, and $150 \%)$ by the standard addition method. At each level, three replicates were injected into a chromatographic system. The mean percentage recovery for itraconazole and terbinafine $\mathrm{HCl}$ was found within a limit of $98-101 \%$, and from percentage recovery results, it was found that the developed method is accurate. The percentage recovery results are tabulated in Tables 4 and 5 .

Table 2: System suitability parameters

\begin{tabular}{lll}
\hline Parameters & Itraconazole & Terbinafine HCl \\
\hline Retention time & 3.469 & 8.705 \\
Tailing factor & 1.08 & 1.15 \\
Number of theoretical plate & 3806 & 5276 \\
\hline
\end{tabular}

Table 3: System precision results

\begin{tabular}{llll}
\hline S. No. & Itraconazole (40 $\mathbf{~ p p m})$ & & Terbinafine HCl (100 ppm) \\
\cline { 2 - 2 } & Peak area & Peak area \\
\hline 1. & 662,869 & $9,209,276$ \\
2. & 663,860 & $9,203,549$ \\
3. & 667,701 & $9,196,756$ \\
4. & 663,904 & $9,203,818$ \\
5. & 667,018 & $9,226,983$ \\
6. & 667,498 & $9,235,940$ \\
Average & 665,475 & $9,212,720$ \\
SD & 2159 & 15,314 \\
\% RSD & 0.32 & 0.17 \\
\hline
\end{tabular}

SD: Standard deviation, RSD: Relative standard deviation

Table 4: Method precision results

\begin{tabular}{lll}
\hline S. No. & Itraconazole & Terbinafine $\mathbf{H C l}$ \\
\cline { 2 - 2 } & \% assay & \% assay \\
\hline 1. & 101.2 & 99.3 \\
2. & 102.0 & 99.6 \\
3. & 101.7 & 100.0 \\
4. & 101.5 & 99.9 \\
5. & 101.4 & 99.5 \\
6. & 101.0 & 98.7 \\
Average & 101.5 & 99.5 \\
SD & 0.36 & 0.47 \\
\% RSD & 0.35 & 0.47 \\
\hline
\end{tabular}

Linearity

The linearity of the developed method was determined at different concentration levels ranging from $20 \mathrm{ppm}$ to $60 \mathrm{ppm}$ for itraconazole and from $50 \mathrm{ppm}$ to $150 \mathrm{ppm}$ for terbinafine HCl. The linearity curve was constructed by plotting peak area versus concentration and the regression coefficient $\left(\mathrm{r}^{2}\right)$ was found to be 0.9989 for itraconazole and 0.9995 for terbinafine hydrochloride. From linearity results, it was found that the developed method is linear (Figs. 6 and 7). Results are shown in Tables 6 and 7.

\section{Robustness}

The developed method was evaluated for robustness by small deliberate changes in optimized method parameters which were done such as

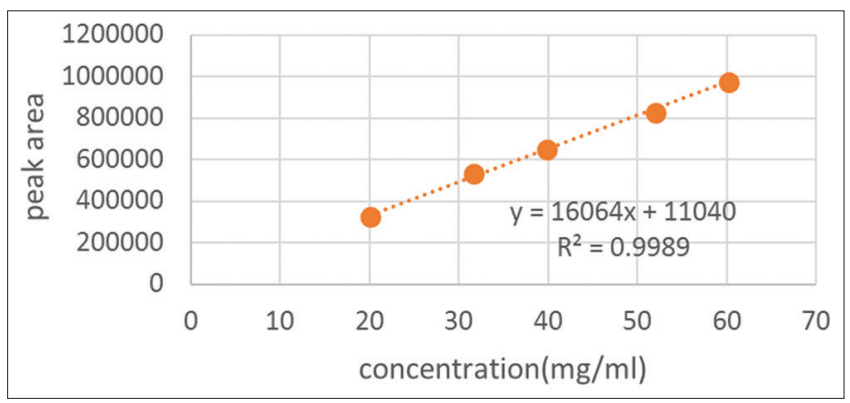

Fig. 6: Linearity graph of itraconazole

Table 5: \% recovery results for itraconazole

\begin{tabular}{lllll}
\hline Level & \% recovery & Average & SD & \% RSD \\
\hline $50 \%$ & 99.0 & 99.7 & 0.70 & 0.70 \\
& 100.4 & & & \\
& 99.6 & 99.9 & 0.25 & 0.25 \\
$100 \%$ & 99.9 & & & \\
& 99.6 & & 0.40 & 0.40 \\
$150 \%$ & 100.1 & 99.4 & & \\
& 99.5 & & & \\
& 99.8 & & & \\
\hline
\end{tabular}

SD: Standard deviation, RSD: Relative standard deviation

Table 6: \% recovery results for terbinafine $\mathrm{HCl}$

\begin{tabular}{lllll}
\hline Level & \% recovery & Average & SD & \% RSD \\
\hline $50 \%$ & 99.7 & 99.4 & 0.49 & 0.49 \\
& 98.8 & & & \\
& 99.6 & 99.9 & 0.06 & 0.06 \\
$100 \%$ & 99.9 & & & \\
& 100 & & & \\
& 99.9 & 99.3 & 1.01 & 1.01 \\
$150 \%$ & 100.4 & & & \\
& 98.4 & & & \\
\hline
\end{tabular}

SD: Standard deviation, RSD: Relative standard deviation

Table 7: Linearity results for itraconazole and terbinafine $\mathrm{HCl}$

\begin{tabular}{lllll}
\hline \multicolumn{2}{l}{ Concentration $(\mathbf{p p m})$} & & \multicolumn{2}{l}{ Area } \\
\cline { 1 - 2 } Itraconazole & Terbinafine HCl & & Itraconazole & Terbinafine HCl \\
\hline 20 & 50 & & 331,698 & $4,371,822$ \\
32 & 80 & & 530,320 & $7,242,916$ \\
40 & 100 & & 833,900 & $9,245,345$ \\
52 & 120 & & $11,074,374$ \\
60 & 150 & & 16,064 & $13,763,467$ \\
Slope & Slope & & 94,174 \\
Intercept & Intercept & & $-277,853$ \\
Correlation & Correlation & & 0.9989 & 0.9995 \\
\hline
\end{tabular}


flow rate $( \pm 0.2 \mathrm{ml})$, wavelength $( \pm 2 \mathrm{~nm})$, and temperature $\left( \pm 2^{\circ} \mathrm{C}\right)$ [15]. It was found that none of the above parameters caused an alteration in the peak area and retention time. The \% RSD was found to be within the limits, and the method was found to be robust. The robustness results are shown in Table 8 .

\section{Solution stability}

Sample solution of itraconazole and terbinafine $\mathrm{HCl}$ was injected at different time intervals and percentage assay was calculated. The solution stability of $24 \mathrm{~h}$ shows that the sample solution can be used over a period of $24 \mathrm{~h}$ without any degradation of the solution and solution stability results are shown in Table 9.

\section{Assay of marketed formulation}

For analysis of marketed formulation (Duofaze: $100 \mathrm{mg}$ itraconazole and $250 \mathrm{mg}$ terbinafine hydrochloride), 10 tablets were weighed and finely powdered was weighed the quantity of powder containing $80 \mathrm{mg}$ of (itraconazole + terbinafine $\mathrm{HCl}$ ) and transfer to a $250 \mathrm{ml}$ volumetric flask and $150 \mathrm{ml}$ of diluent was added. The flask was sonicated for 30-45 min with intermittent shaking. Volume was adjusted up to mark with diluent. The sample solution was centrifuged at $5000 \mathrm{rpm}$ for 10 min and filtered through Whatman filter paper. The percentage assay for the marketed formulation was found to be $100.5 \%$ for itraconazole and $99.8 \%$ for terbinafine $\mathrm{HCl}$ as shown in Table 10 .

\section{Forced degradation studies}

Forced degradation studies were carried out on itraconazole and terbinafine $\mathrm{HCl}$ marketed tablet formulation by treating the marketed formulation under stress conditions such as acidic, alkaline, hydrolysis, thermal, and oxidative conditions to estimate the ability of the developed method to separate itraconazole and terbinafine $\mathrm{HCl}$ from its degradation products as shown in Figs. 8-12. The forced degradation results are within the limit and it is tabulated in Table 11.

\section{Acid degradation}

In acid degradation condition $(0.1 \mathrm{~N} \mathrm{HCl})$, both itraconazole and terbinafine $\mathrm{HCl}$ degraded and degradation was $17.2 \%$ and $0.1 \%$ for itraconazole and terbinafine $\mathrm{HCl}$, respectively, and no peak of degradation of the product was observed in the chromatogram (Fig. 8).

Table 8: Robustness results for itraconazole and terbinafine $\mathrm{HCl}$

\begin{tabular}{llllll}
\hline Parameters & \multicolumn{2}{l}{ Itraconazole } & & \multicolumn{2}{l}{ Terbinafine $\mathbf{H C l}$} \\
\cline { 2 - 3 } \cline { 6 - 6 } & RT & \% assay & & RT & \% assay \\
\hline Minus flow $(1.0 \mathrm{ml} / \mathrm{min})$ & 4.145 & 101.1 & & 10.410 & 99.9 \\
Plus flow $(1.4 \mathrm{ml} / \mathrm{min})$ & 2.985 & 101 & & 7.432 & 99.7 \\
Minus temperature $\left(28^{\circ} \mathrm{C}\right)$ & 3.485 & 101.4 & & 8.747 & 100.1 \\
Plus temperature $\left(32^{\circ} \mathrm{C}\right)$ & 3.483 & 100.7 & & 8.744 & 98.7 \\
Minus wavelength $(223 \mathrm{~nm})$ & 3.489 & 101.7 & & 8.742 & 100.2 \\
Plus wavelength $(227 \mathrm{~nm})$ & 3.487 & 100 & & 8.729 & 98.2 \\
\hline
\end{tabular}

RT: Retention time

Table 9: Solution stability results

\begin{tabular}{lll}
\hline Time interval & \multicolumn{1}{l}{ Itraconazole } & Terbinafine $\mathbf{H C l}$ \\
\cline { 2 - 2 } & \% assay & \% assay \\
\hline Initial & 101.8 & 100.6 \\
$6 \mathrm{~h}$ & 102.4 & 100.7 \\
$16 \mathrm{~h}$ & 101.7 & 100.4 \\
$24 \mathrm{~h}$ & 101.4 & 99.9 \\
\hline
\end{tabular}

Table 10: \% assay of marketed formulation

\begin{tabular}{lll}
\hline Tablet & Drug & \% assay \\
\hline $\begin{array}{l}\text { Duofaze (itraconazole } 100 \mathrm{mg}+ \\
\text { terbinafine } \mathrm{HCl} 250 \mathrm{mg})\end{array}$ & Itraconazole & 100.5 \\
\hline
\end{tabular}

\section{Base degradation}

In alkali degradation $(0.1 \mathrm{~N} \mathrm{NaOH})$, both itraconazole and terbinafine $\mathrm{HCl}$ degraded and degradation was $4.3 \%$ and $0.7 \%$ for itraconazole and terbinafine $\mathrm{HCl}$, respectively, and no peak of degradation of the product was observed in the chromatogram (Fig. 9).

\section{Water hydrolysis degradation}

In hydrolysis degradation, both itraconazole and terbinafine $\mathrm{HCl}$ did not get degrade and percentage degradation was $0.05 \%$ and $0.4 \%$ for itraconazole and terbinafine $\mathrm{HCl}$, respectively; no peak of degradation of the product was observed in the chromatogram (Fig. 10).

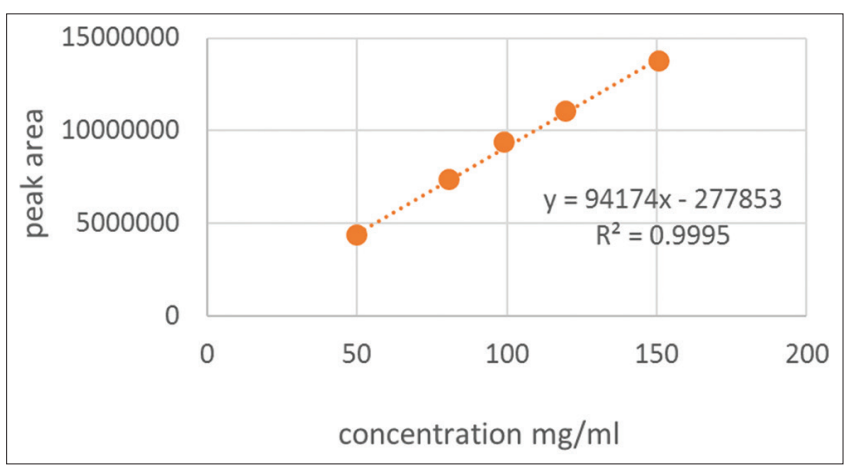

Fig. 7: Linearity graph of terbinafine $\mathrm{HCl}$

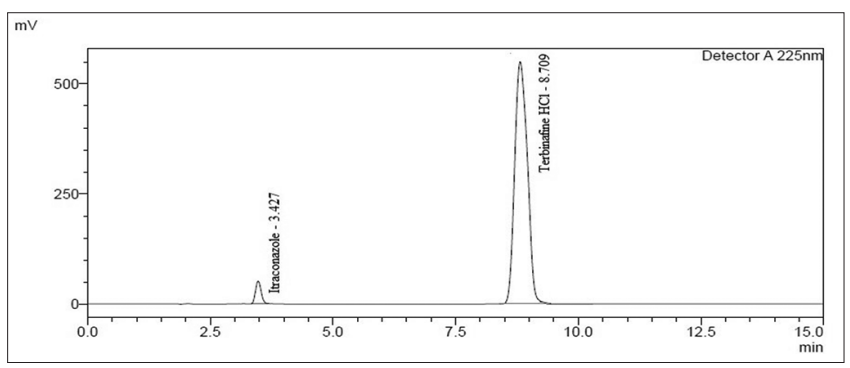

Fig. 8: Chromatogram of acid degradation

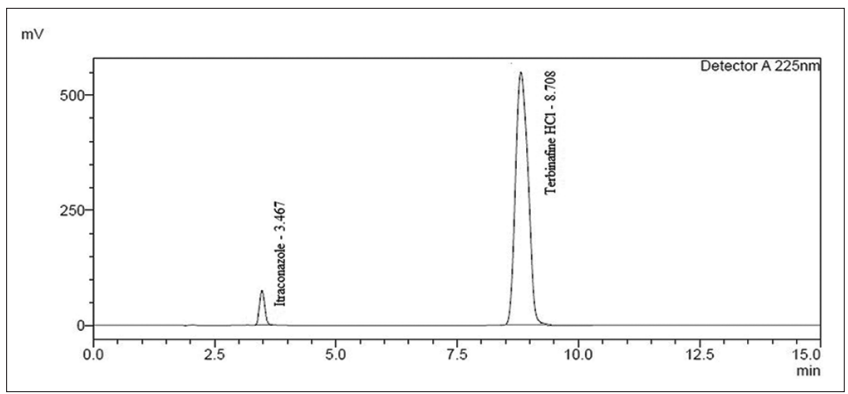

Fig. 9: Chromatogram of base degradation

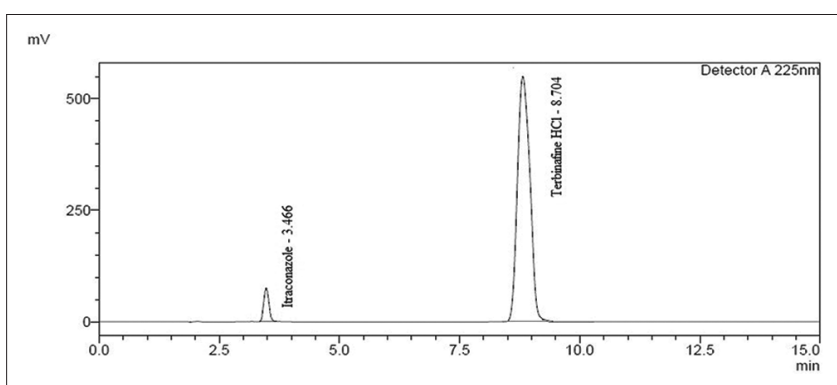

Fig. 10: Chromatogram of water hydrolysis degradation 
Table 11: Forced degradation studies results of itraconazole and terbinafine $\mathrm{HCl}$

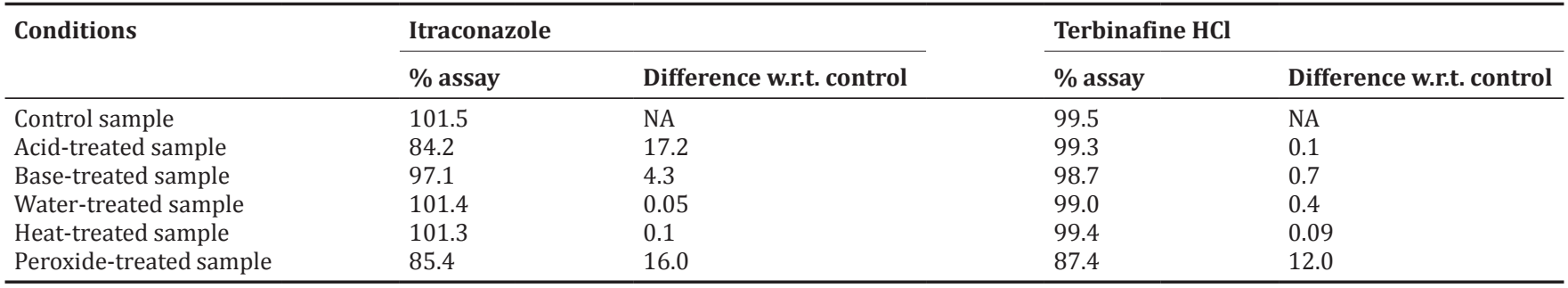

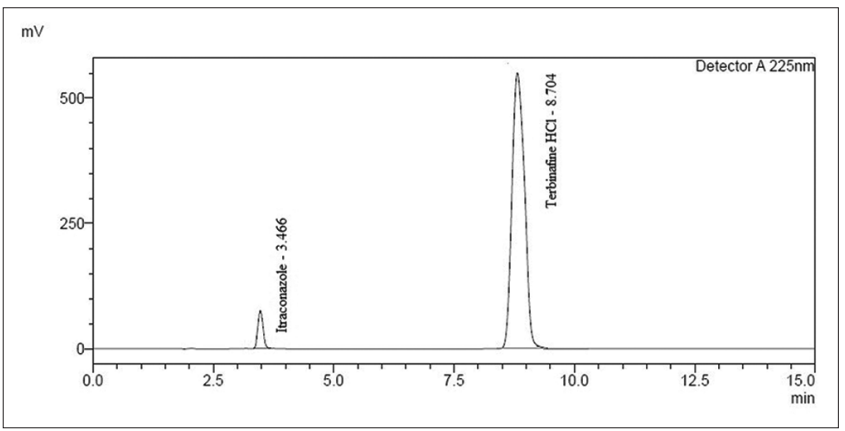

Fig. 11: Chromatogram of thermal degradation

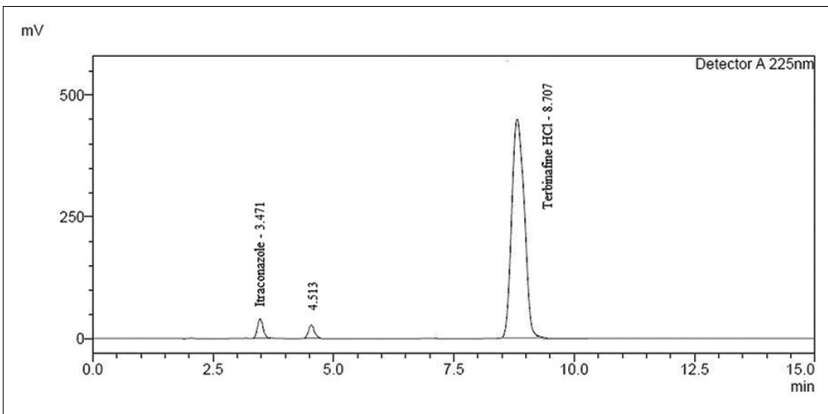

Fig. 12: Chromatogram of oxidative degradation

\section{Thermal degradation}

In thermal degradation, both itraconazole and terbinafine $\mathrm{HCl}$ did not degrade and percentage degradation was $0.1 \%$ and $0.09 \%$ for itraconazole and terbinafine $\mathrm{HCl}$, respectively; no peak of degradation of the product was observed in the chromatogram (Fig. 11).

\section{Oxidative degradation}

In oxidative degradation $\left(30 \% \mathrm{H}_{2} \mathrm{O}_{2}\right)$, both itraconazole and terbinafine $\mathrm{HCl}$ were get degraded. The percentage degradation was $16.0 \%$ and $12.0 \%$ for itraconazole and terbinafine $\mathrm{HCl}$, respectively. The degradant product peak was observed at $4.513 \mathrm{~min}$ and from literature; it may be itraconazole oxidative degradation product (Fig. 12) [16].

\section{CONCLUSION}

The stability-indicating method has been developed and validated for the simultaneous estimation of itraconazole and terbinafine $\mathrm{HCl}$ in bulk and pharmaceutical tablet dosage form. The developed method was successfully applied for forced degradation studies of itraconazole and terbinafine $\mathrm{HCl}$. Forced degradation results indicate that the developed method can be successfully used for the separation of degraded products from the sample. The developed method is novel, simple, cost effective, and accurate for the determination of itraconazole and terbinafine $\mathrm{HCl}$, and it can be used for routine analysis of the itraconazole and terbinafine $\mathrm{HCl}$ in the formulation.

\section{ACKNOWLEDGMENT}

The authors are thankful to our Principal Dr. Mrs. Sudha Rathod, Oriental College of Pharmacy, Sanpada, Navi Mumbai, for providing a platform and facility to conduct research work. The authors are thankful to Alkem Laboratories for providing a gift sample of itraconazole and terbinafine $\mathrm{HCl}$

\section{AUTHORS' CONTRIBUTIONS}

All the authors have contributed equally.

\section{CONFLICTS OF INTEREST}

The author declares that there are no conflicts of interest regarding the publication of this article.

\section{REFERENCES}

1. Kumudhavalli V. Isocratic RP-HPLC, UV method development and validation of itraconazole in capsule dosage form. Int J Pharm Sci Res 2011;2:3269-71

2. Gupta A, Bharti T, Salahuddin NN. Analytical method development and validation of terbinafine $\mathrm{HCl}$ in formulated product using reverse phase ultra-performance liquid chromatography (RP-UPLC). Eur J Biomed Pharm Sci 2016:3:542-7.

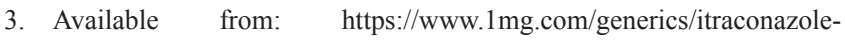
terbinafine- 405211.

4. Rao TM, Ratna VJ, Rao SY, Kumar HT. Development and validation of RP-HPLC method for the determination of itraconazole in bulk and capsule dosage form. Int J Pharm Sci Rev Res 2015;31:39, 221-5.

5. Gupta MK, Rajput S. Development and validation of RP-HPLC method for quantitation of itraconazole in tablets dosage form. Int J Pharm Res Rev 2015;4:23-9.

6. Hamsa K, Mohamed AA. High performance liquid chromatography method for the determination of terbinafine hydrochloride in semi solids dosage form. Int J Pharm Sci Rev Res 2013;21:58-61.

7. Patel MM, Patel HD, Development and validation of RP-HPLC method for simultaneous estimation of terbinafine hydrochloride and mometasone furoate in combined dosage form. Int J Pharm Pharm Sci 2016;6:106-9.

8. Rao DD, Sait SS, Reddy SP, Mukkanti K. A stability indicating LC method for the assay estimation of itraconazole in pharmaceutical dosage form. Anal Chem Indian J 2009;8:271-6.

9. International Conference on Harmonization. Stability Testing of New Drug Substances and Products (Q1AR2). International Conference on Harmonization. Geneva: IFPMA; 2003

10. International Conference on Harmonization of Technical Requirements for Registration of Pharmaceuticals for Human use. Validation of Analytical Procedures: Text and Methodology. ICH; 2005.

11. Food and Drug Administration. Reviewer Guidance Validation of Chromatographic Methods. Centre for Drug Evaluation and Research (CDER). Food and Drug Administration; 1994. p. 2.

12. Food and Drug Administration. ORA Validation and Verification Guidance for Human Drug Analytical Methods. Food and Drug Administration; 2003. p. 1.

13. Blessy M, Patel RD, Prajapati PN, Agrawal YK. Development of forced degradation and stability indicating studies of drugs-A review. J Pharm Anal 2014;4:159-65.

14. Jain V, Shaikh MS. Simultaneous RP-HPLC analysis of quercetin and kaempferol in different plant parts of Cissus quadrangularis. Int $\mathrm{J}$ Pharm and Pharm Sci 2016;8:138-42.

15. Marineni B, Reddy TS. Development and validation of stabilityindicating RP-HPLC assay method for azacitidine and its bulk drug. Int J Pharm Pharm Sci 2014; 6:240-4.

16. Badawey AM, Lamie NT, Abd El-Aleen AB, Selective determination of itraconazole in the presence of its oxidative degradation product. Anal Chem Indian J 2013;12:48-55. 